\title{
PENGUKURAN TINGKAT KESELARASAN TATA KELOLA TEKNOLOGI INFORMASI MENGGUNAKAN COBIT 5 PADA PEMERINTAH SULAWESI UTARA
}

\author{
Brian Gamaliel $^{1}$, Yaulie Rindengan ${ }^{2}$, Stanley Karouw ${ }^{3}$ \\ Teknik Informatika Universitas Sam Ratulangi. Manado, Jl. Kampus Unsrat Bahu, Manado 95115 \\ 120216019@student.unsrat.ac.id ${ }^{1}$, Rindengan@unsrat.ac.id ${ }^{2}$, stanley.karouw@unsrat.ac.id ${ }^{3}$
}

\begin{abstract}
Abstrak - Pemerintah Sulawesi Utara memiliki 46 Satuan Kerja Perangkat Daerah memiliki tugas pokok dan fungsi melayani masyarakat Sulawesi Utara. Setiap Satuan Kerja Perangkat Daerah berusaha menerapkan teknologi informasi dan komunikasi agar menciptakan pelayanan yang efektif, efisien transparan dan akuntabel. Untuk mengetahui tingkat keselarasan implementasi teknologi informasi dan komunikasi pada masing-masing Satuan Kerja Perangkat Daerah tersebut itu diperlukan adanya assement, dengan menggunakan Cobit, dengan 4 domain, yakni Domain Evaluate, Direct and Monitor, Domain Align, Plan and Organize, Domain Build, Acquire and Operate dan Domain Deliver, Service and Support dan 11 sub domain. Hasil pengukuran menunjukkan bahwa tingkat keselarassan saat ini (to-as) untuk 11 subdomain adalah 6 sub domain mencapai tingkat 1 (Performed Process) dan 5 sub domain mencapai tingkat 0 (Incomplete Process). Rekomendasi untuk 5 sub domain yang mencapai tingkat 0 adalah perbaikan proses untuk mencapai tingkat 1 sedangkan rekomendasi untuk 6 sub domain yang mencapai tingkat 1 adalah perbaikan proses untuk mencapai tingkat 2.
\end{abstract}

Kata kunci: COBIT 5, Keselarasan TI, Tata Kelola TI

\section{PENDAHULUAN}

Penerapan teknologi informasi dan komunikasi (TIK) saat ini telah menjadi kebutuhan di segala aspek baik individual, kelompok/organisasi bahkan lembaga pemerintahan [1]. Implementasi TIK dalam pemerintahan dimaksudkan agar setiap level pemerintahan dapat meningkatkan pelayanan public sesuai amanat Undang-Undang Nomor 25 Tahun 2009 [2] tentang eGovernment dan Instruksi Presiden No3 Tahun 2003 [3] tentang Pelayanan Publik. Pelayanan public yang baik dapat meningkatkan kesejahteraan masyarakat pada umumnya. Pelaksanaan pemerintahan dengan berbasis elekronik atau berbasis TIK akan memungkinkan setiap lembaga pemerintahan mencapai pemerintahan yang efisien, efektif, tranparan dan akuntabel [4].
Hasil pengolahan data kusioner pada 46 Satuan Kerja Perangkat Daerah (disingkat SKPD) di Provinsi Sulawesi Utara menunjukkan beberapa permasalahan, sebagai berikut: 1) Penyediaan sarana dan prasarana TIK yang belum optimal, sehingga menyebabkan adanya kesenjangan akses informasi; 2) Belum optimalnya sistem pelayanan informasi publik sehingga mengakibatkan kurangnya partisipasi masyarakat dalam pembangunan; 3) Kondisi budaya kerja yang belum terbangun dengan kuat, dan sumber daya manusia yang menguasai Teknologi Informatika.

Paper ini akan menjawab permasalahan terkait bagaimana mengukur keselarasan TIK di Provinsi Sulawesi Utara. Seperti yang telah dikemukakan pada paragraf diatas terdapat permasalahan terkait efisiensi dan efektifitas dalam pengolahan TIK, di tandai dengan adanya sarana dan prasarana yang belum optimal sehingga menyebabkan adanya kesenjangan akses informasi dan kurangnya partisipasi masyarakat dalam pembangunan. Untuk lebih memahami permasalahan efesiensi dan efektifitas tersebut diperlukan ada pengukuran tingkat keselarasan TIK pada masing-masing SKPD. Pengukuran keselarasan TIK ini dapat memberikan gambaran kondisi sebenarnya terkait pengelolaan TIK pada bidang tata kelola tertentu sehingga dari gambaran kondisi ini dapat diberikan solusi untuk permasalahan kurang optimalnya efisiensi dan efektifitas TIK di Provinsi Sulawesi Utara.

\section{LANDASAN TEORI}

\section{A. TATA KELOLA TEKNOLOGI INFORMASI DAN KOMUNIKASI}

Definisi tata kelola teknologi informasi telah dikemukakan oleh para ahli, diantaranya sebagai berikut :

i. Proses pengelolaan teknologi informasi harus terlebih dahulu didefinisikan oleh sebuah 
organisasi sebelum yang bersangkutan dapat merancang struktur divisi atau unit teknologi informasi yang sesuai; karena secara prinsip, terlepas dari jenis atau bentuk struktur organisasi unit teknologi informasi, sejumlah proses tata kelola harus dimiliki oleh perusahaan[5].

ii. Organisasi harus memiliki strategi dan mekanisme yang jelas dalam usahanya untuk menyatukan keempat elemen strategis yaitu proses, struktur, teknologi, dan sumber dayamanusia. Untuk perusahaan yang ingin belajar menuju pada tataran "best practice", COBIT dapat dijadikan sebagai acuan awal karena konsep tersebut dibangun dengan menggunakan paradigma manajemen moderen yang sangat cocok diterapkan [6]

Dari kedua definisi tersebut dapat disimpulkan bahwa yang dimaksud dengan tata kelola teknologi informasi adalah upaya menjamin pengelolaan teknologi informasi agar mendukung bahkan selaras dengan strategi bisnis suatu enterprise yang dilakukan oleh dewan direksi, manajemen eksekutif, dan juga oleh manajemen teknologi informasi. Tata kelola TIK harus mampu merefleksikan adanya penerapan prinsip-prinsip organisasi yang memfokuskan pada kegiatan manajemen dan penggunaan TIK untuk pencapaian tujuan organisasi dan harus mempertimbangkan risiko investasi TI yang dilakukan.

\section{B. KESELARASAN TIK}

(Tallon dan Kremer, 2003) [7] mendefinisikan keselarasan TIK mendukung dan didukung oleh strategi bisnis istilah didukung menjelaskan strategi bisnis yang mengarah pemnafaatan teknologi untuk menggali kesempatankesempatan bisnis yang baru, sedangkan istilah mendukung menjelaskan pemanfaatan sepenuhnya dari kapabilitas TIK yang ada. [8] menjelaskan keselarasan TIK sebagai kecocokan strategi (strategic fit) dan integrasi fungsional ( functional integration) antara strategi bisnis, strategi TIK, infrastuktur bisnis dan infrastuktur TIK.

(Wowor dan Karouw, 2012) [9] menyatakan bahwa diperlukan adanya dokumen rencana strategis pada pemerintah Sulawesi Utara agar setiap manfaat implementasi TIK pada masing-masing SKPD dapat diidentifikasi, diklasifikasi dan diukur. Proses identifikasi, klasifikasi dan pengukuran manfaat implementasi TIK pada pemerintah daerah, khususnya provinsi Sulawesi Utara dapat menjadi masukan dalam pengukuran tingkat keselarasan TIK pada masing-masing SKPD. terdapat 2 manfaat spesifik dari implementasi TIK di provinsi Sulawesi Utara, yakni mempercepat proses pelayanan dan mencegah adanya fraud (atau kesalahan).

\section{COBIT 5}

(ISACA, 2013) [10] merupakan seperangkat kerangka kerja tata kelola teknologi informasi yang memungkinkan para pengambil keputusan untuk memangkas jarak (gap) antara resiko bisnis (business risk), masalah teknis (technical issue) dan control requirement. COBIT merupakan standar tata kelola TIK yang dikembangkan oleh IT Governance Institute (ITGI), yaitu sebuah organisasi yang melakukan studi tentang model tata kelola TIK yang berbasis di Amerika Serikat. COBIT adalah kerangka kerja tata kelola TIK (IT governance framework) dan kumpulan alat yang mendukung dan memungkinkan para manajer untuk menjembatani jarak (gap) yang ada antara kebutuhan yang dikendalikan (control requirements), masalah teknis (technical issues) dan risiko bisnis (business risk). Berbeda dengan standarstandar tata kelola TIK lainnya, COBIT mempunyai cakupan yang lebih luas, komprehensif dan mendalam dalam melihat proses pengelolaan TIK. Selain sebagai framework tata kelola TIK, COBIT juga dapat digunakan sebagai framework untuk melakukan audit dan evaluasi TIK.

(ISACA, 2013) [10] COBIT 5 merupakan sebuah perkembangan strategis yang menyediakan panduan generasi berikutnya dari ISACA pada tata kelola dan manajemen untuk aset TIK organisasi. COBIT 5 membantu organisasi menciptakan nilai TIK yang optimal dengan menjaga keseimbangan antara mewujudkan manfaat dan mengoptimalkan identifikasi tingkat risiko dan sumber daya yang digunakan. The COBIT 5 principles and enablers bersifat umum dan bermanfaat untuk semua ukuran organisasi, baik itu komersil atau penyedia layanan publik.

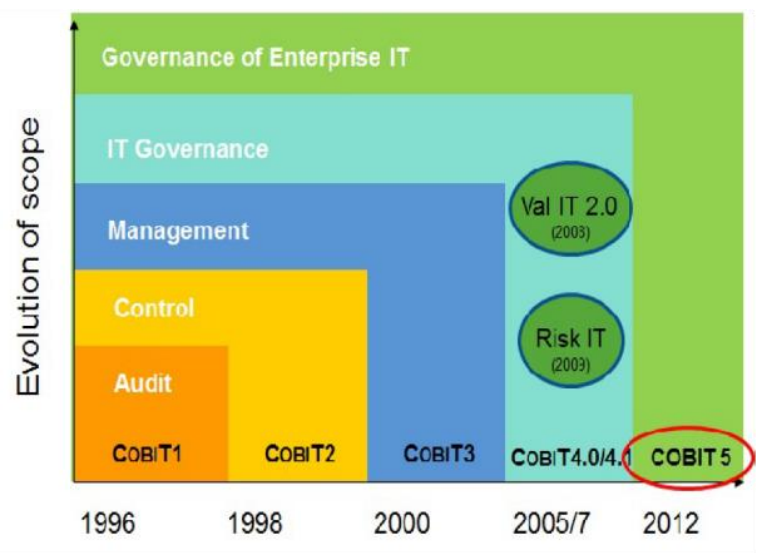

Gambar 1. Perkembangan Framework COBIT [10] 
COBIT 5 didasarkan pada lima prinsip kunci tata kelola dan manajemen TIK organisasi yaitu (1) Pemenuhan kebutuhan stakeholder, (2) Melindungi titik-titik penting organisasi, (3) Penggunaan sebuah framework terintegrasi, (4) Memungkinkan pendekatan secara keseluruhan, dan (5) Memisahkan tata kelola dengan manajemen. Untuk mendukung pencapaian prinsip kunci tata kelola dan manajemen TIK tersebut.

\section{Penelitian Terdahulu}

Terdapat beberapa penelitian sebelumnya yang menjadi tinjauan dalam pengukuran tingkat kematangan TI pada perusahaan maupun instansi pemerintahan. Sebagai bahan tinjauan dalam penelitian ini akan dicantumkan beberapa hasil penelitian sebelumnya yang dilakukan oleh beberapa peneliti,

1. (Arif Lutfianto, 2013)[11] meningkatkan keefektifan penggunaan teknologi informasi serta mendukung efisiensi dalam organisasi yangbertujuan untuk mengetahui tingkat kapabilitas ( capability level) dan harapan pihak pengelola mengenai pengaturan dan pemeliharaan kerangka tata kelola. Hubungan dengan penelitian ini adalah menggunakan tingkat kapabilitas ( capability level) dalam mengukur tata kelola yang ada dalam Pemerintah Sulawesi Utara.

2. (Nurrahmi Fitri, 2015)[12] Pemilihan domain COBIT bertujuan agar proses yang dibahas sesuai dengan tujuan yang diharapkan. Berdasarkan hasil analisa dokumen bisnis dan hasil survey nantinya maka akan mendapatkan satu tujuan umum stakeholder yang memiliki kaitan erat dengan permasalahan yang ada. Dalam penelitian ini juga mengindentifikasikan Domain COBIT dengan mempelajari dokumen bisnis dan hasil survey.

3. (Abdul Hakim, 2014)[13] dalam penilitiannya yang bertujuan untuk mengetahui sejauh mana pengelolaan dan pemanfaatan TIK dalam meningkatkan pelayanan TIK Hubungan dengan penelitian ini adalah tujuan yang sama yaitu meningkatkan pelayanan publik TIK di Pemerintah Sulawesi Utara.

4. (Burdefira, 2013)[14] menjelaskan dalam penelitiannya tujuh langkah yang perlu dilakukan untuk membangun Sistem Tata Kelola Teknologi Informasi: Mengidentifikasi kondisi saat ini. (2) Mengidentifikasi masalah pada implementasi Teknologi Informasi. (3)
Mengukur Nilai dan Risiko TIK. (4) Seleksi yang tepat dan sistem TIK kritis. (5) Mengukur tingkat kematangan sata ini serta target tingkat kematangan dan memberikan sasaran yang tepat terhadap implemntasi tata kelola teknologi inforamsi pada Pemerintah Kota Padang. (6) Menganalisis kondisi kesenjangan TIK. (7) Mengembangkan prosedur yang terorganisir dari sistem TIK.sama dengan penelitian ini mengikuti 7 langkah seperti yang diatas.

5. (Soni Susanto,2015)[15] menguraikan mengenai tahapan proses penelitian yang akan dilakukan. Tahapan pertama adalah pemilihan domain COBIT, pengumpulan data, pengolahan data, analisa data, dan pembuatan rekomendasi untuk mencapai kondisi yang diharapkan. Hubungan dengan penelitian ini adalah mengikuti seluruh tahapan agar mendapatkan rekomendasi tata kelola TIK.

6. (Pasquini \& Galiè, 2013)[16] Telah melakukan penelitian dengan judul penelitian "COBIT 5 and the Process Capability Model. Improvements Provided for IT Governance Process". Penelitian ini masih membahas tentang perbandingan antara metode praktik COBIT dan metode lainnya berikut masalah yang di ambil oleh penulis, TIK governance dan manajemen di Pemerintah memainkan peran penting dalam menghasilkan nilai bagi para pemangku kepentingan.

\section{METODOLOGI PENELITIAN}

Pada bagian ini menjelaskan Kerangka pemikiran dimana terdapat rincian tentang bahan atau materi, alat, urutan langkah-langkah yang dibuat secara sistematis, logis sehingga dapat dijadikan pedoman yang jelas dan mudah untuk menyelesaikan permasalahan, analisis hasil dan kesulitan-kesulitan yang dihadapi. Lokasi penelitian dilakukan dengan studi kasus tata kelola TIK di lingkungan Pemerintah Pemerintah Sulawesi Utara. Urutan langkah-langkah penelitian penyelesaian masalah dapat dilihat pada gambar 2.

Tahapan persiapan peneliti melakukan observasi, telaah dokumen bisnis dan studi literatur dengan menggunakan dokumen-dokumen yang terkait TIK dan informasi dengan menambahkan masukanmasukan dari Pemerintah Sulawesi Utara. Keluaran yang di dapatkan dari tahap persiapan yaitu identifikasi permasalahan TIK yang ada dalam Pemerintah Sulawesi Utara. 


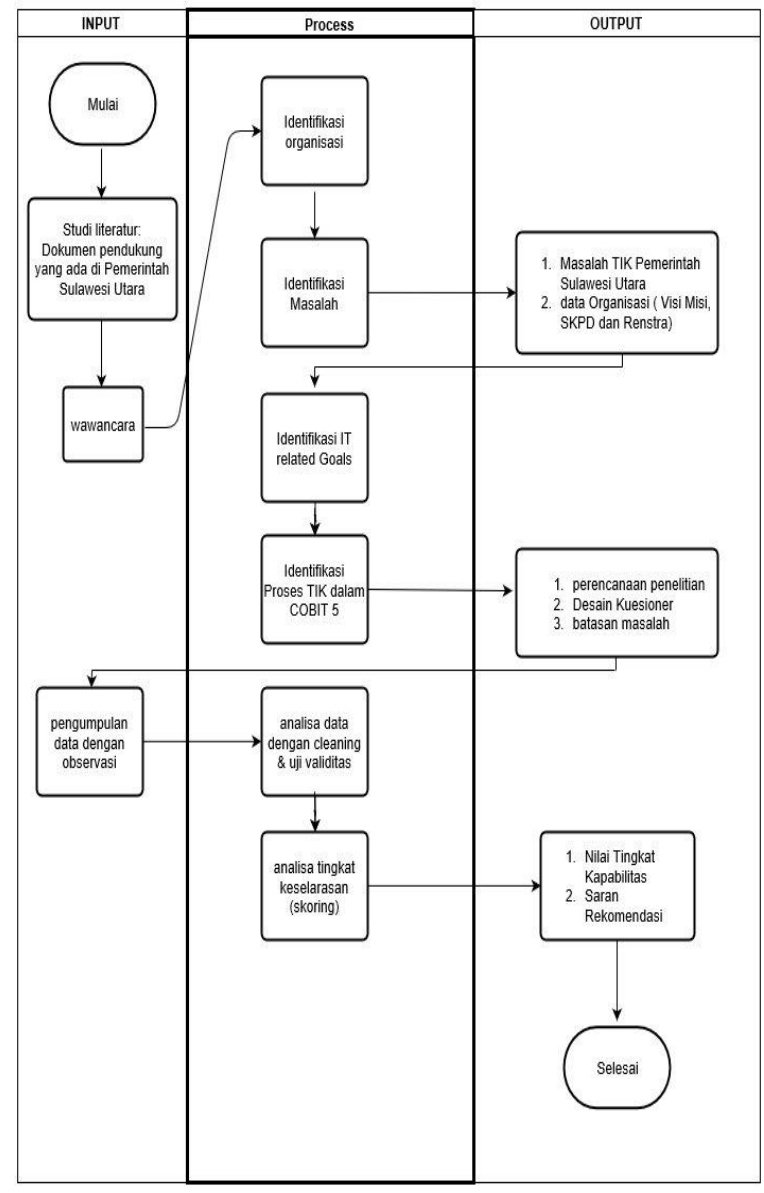

Gambar 2. Alur Penelitian

Pada tahapan Desain penelitan dari hasil identifikasi masalah TIK Pemerintah Sulawesi Utara diitambahkan dengan informasi organisasi (visi misi, daftar SKPD dan Renstra) maka data tersebut dimasukkan dalam metode COBIT 5 Goal. Metode tersebut adalah mekanisme untuk menerjemahkan kebutuhan-kebutuhan dalam hal ini stakeholderstakeholder dalam lingkungan Pemprov Sulawesi Utara untuk ditindaklanjuti secara spesifik dan disesuaikan dengan Visi dan Misi Pemerintah Provinsi Sulawesi Utara tujuan yang berkaitan dengan TIK dan tujuan dari enabler. Terjemahan ini memungkinkan menetapkan tujuan yang spesifik di setiap tingkatan dan di setiap area organisasi untuk mendukung tujuantujuan dan persyaratan stakeholder, dan dengan demikian secara efektif mendukung keselarasan antara kebutuhan organisasi dan solusi dan layanan TIK. Gambar 3 memperlihatkan COBIT 5 goals cascade secara umum. Keluaran yang didapatkan dari tahapan tersebut yaitu desain perencanaan, kuesioner dan batasan masalah dalam penilitian.

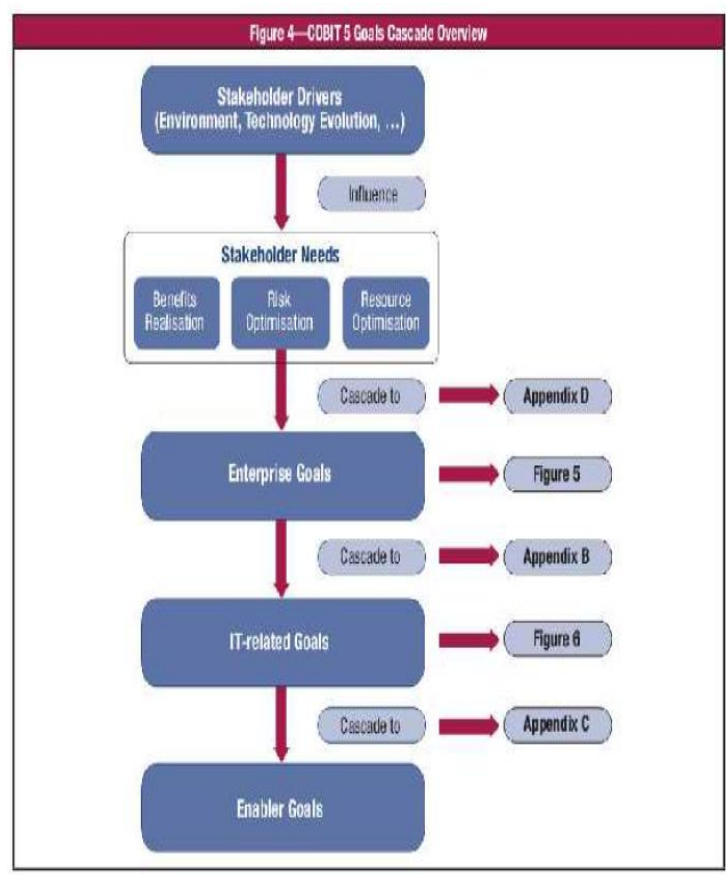

Gambar 3 COBIT 5 Goals Cascade

[17]

Tahapan pengumpulan dan analisa data menggunakan metode penelitian deskriptif kualitatif Karena, pengukuran tingkat kapabilitas tata kelola TIK menggunakan data kualitatif yang diperoleh dari hasil diskusi, kuesioner dan wawancara berdasarkan proses dalam COBIT 5.ISACA memberikan prosedur untuk melakukan audit atau menilai adanya dokumen formalitas (adanya kontrak, SLA atau proses dokumentasi prosedur) menggunakan pilihan jawaban "ya" atau "tidak" yang tegas terhadap proses pengelolaan tata kelola TI dari aparatur yang membidangi TIK [18].Pengolahan kuesioner dilakukan untuk mendapatkan nilai kapabilitas dari masing-masing proses. Skala yang digunakan untuk menilai kapabilitas tingkat 1 dan tingkat berikutnya adalah dalam bentuk presentase implementasi proses yang dijalankan. Pengolahanan ini dilakukan dengan menghitung presentase untuk setiap jawaban diperoleh dengan membagi frekuensi yang diperoleh dengan jumlah atribut proses, kemudian dikalikan 100\% [19]. Rumus untuk memperoleh presentase proses sebagai berikut :

Tabel 1 Kategori Presentase

\begin{tabular}{|c|c|}
\hline PRESENTASE & KATEGORI \\
\hline$<15 \%$ & $\mathrm{~N}$ (not achieved) - tidak tercapai \\
\hline $15 \%-50 \%$ & $\begin{array}{c}\mathrm{P}(\text { partially achieved }) \text { - sebagaian } \\
\text { tercapai }\end{array}$ \\
\hline $50,01 \%-85 \%$ & $\begin{array}{c}\text { L (largely achieeved }) \text { - sebagian besar } \\
\text { tercapai }\end{array}$ \\
\hline $85,01 \%-100 \%$ & $\begin{array}{c}\mathrm{F}(\text { fully achieved }) \text { - sepenuhnya } \\
\text { tercapai }\end{array}$ \\
\hline
\end{tabular}




$$
P=\frac{f}{n} \times 100 \%
$$

Keterangan :

$\mathrm{P}=$ presentase $; \mathrm{f}=$ Frekuensi dari jawaban yang dipilih ; $\mathrm{n}=$ jumlah pertanyaan; $100 \%=$ konstanta

Presentase yang diperoleh dengan hasil perhitungan di atas, akan dimasukkan ke dalam ketegori dalam tabel 1 .

Dari hasil pengumpulan dan analisa data ditemukan nilai tingkat kapabilitas dalam tata kelola TIK Pemerintah Sulawesi Utara sehingga dalam tahapan penyusunan laporan peneliti Sudah pada tahap pemberian rekomendasi merujuk pada hasil dari nilai tingkat kapabilitas, yang kemudian rekomendasi perbaikan ini adalah saran - saran perbaikan yang sesuai dengan penjelasan COBIT 5 untuk diberikan kepada Pemerintah Sulawesi Utara.

\section{HASIL DAN PEMBAHASAN}

\section{A. Pengujian Validalitas dan Reabilitas Hasil kusioner}

berdasarkan data dikumpulkan pertanyaan yang ada dalam kusioner jumlahnya yaitu 111 pertanyaan yang terdiri dari 11 sub domain yang digunakan. Hasil dari keseluruhan validitas kusioner yaitu 98,89 sehingga data kusioner yang dikumpulkan bisa dikatakan valid untuk digunakan dalam penilitian.

Tabel 2. validitas keseluruhan kusioner

\begin{tabular}{|c|c|}
\hline Pertanyaan yang Valid & $\begin{array}{c}\text { Pertanyaan yang tidak } \\
\text { valid }\end{array}$ \\
\hline 102 pertanyaan & 9 pertanyaan \\
\hline \multicolumn{2}{|c|}{ Validitas hasil kusioner $(\mathbf{1 0 2} \mathbf{X} \mathbf{1 0 0}) / \mathbf{1 1 1}=$} \\
$\mathbf{9 8 , 8 9}$
\end{tabular}

B. Hasil Pengukuran Tingkat Keselarasan

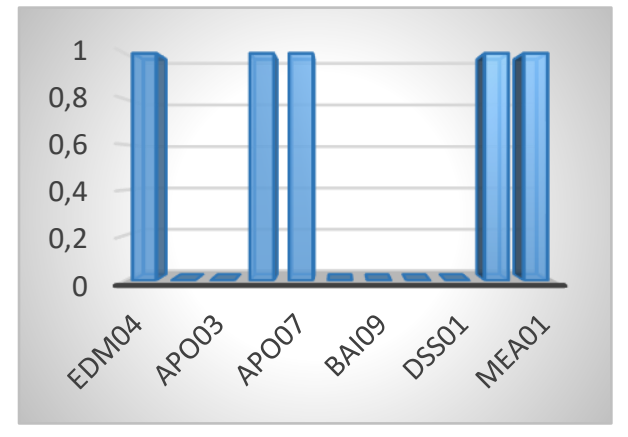

Gambar 4. Tingkat Keselarasan Seluruh proses
Penilaian akan tingkat kapabilitas COBIT mengacu pada standar Process Assesment Model (PAM) dari ISACA. Penilaian dilakukan pada 11 proses COBIT yang dipilih sesuai dengan hasil mapping IT-Related Goals yakni optimalisasi aset TI, sumber daya dan kapabilitas terhadap proses TI yang ada di Pemerintah Sulawesi Utara. Pada gambar 4 berikut menunjukkan pencapaian tingkat kapabilitas atas proses yang telah diukur. Target tingkat keselerasan untuk seluruh proses yang dievaluasi adalah 2,00 untuk mempermudah dalam mengetahui seberapa besar gap yang ada antara target penelitian dengan yang telah dicapai saat ini, dapat dilihat pada tabel 3 dan 4.

Tabel 3. Proses Cobit yang berada pada tingkat 0

\begin{tabular}{|l|l|c|c|c|}
\hline NO & Nama Proses & $\begin{array}{l}\text { Target } \\
\text { proses }\end{array}$ & $\begin{array}{l}\text { Proses } \\
\text { Saat } \\
\text { ini }\end{array}$ & GAP \\
\hline 1 & $\begin{array}{l}\text { APO01 - Manajemen } \\
\text { Kerangka Bidang TI }\end{array}$ & 1 & 0 & 1 \\
\hline 2 & $\begin{array}{l}\text { APO03 - Manajemen } \\
\text { Renstra TI }\end{array}$ & 1 & 0 & 1 \\
\hline 3 & $\begin{array}{l}\text { BAI04 - Manajemen } \\
\text { Ketersediaan Dan } \\
\text { Kapasitas }\end{array}$ & 1 & 0 & 1 \\
\hline 4 & $\begin{array}{l}\text { BAI09 - Manajemen } \\
\text { Aset }\end{array}$ & 1 & 0 & 1 \\
\hline 5 & $\begin{array}{l}\text { BAI10 - Manajemen } \\
\text { Konfigurasi }\end{array}$ & 1 & 0 & 1 \\
\hline 6 & $\begin{array}{l}\text { DSS01 - Manajemen } \\
\text { Operasional }\end{array}$ & 1 & 0 & 1 \\
\hline
\end{tabular}

Tabel 4. Proses Cobit yang berada pada tingkat 1

\begin{tabular}{|l|l|c|c|c|}
\hline NO & Nama Proses & $\begin{array}{l}\text { Target } \\
\text { proses }\end{array}$ & $\begin{array}{l}\text { Proses } \\
\text { Saat } \\
\text { ini }\end{array}$ & GAP \\
\hline 1 & $\begin{array}{l}\text { EDM04 - Memastikan } \\
\text { Pengoptimalan Sumber } \\
\text { Daya }\end{array}$ & 2 & 1 & 1 \\
\hline 2 & $\begin{array}{l}\text { APO04 - Mnajemen } \\
\text { Inovasi }\end{array}$ & 2 & 1 & 1 \\
\hline 3 & $\begin{array}{l}\text { APO07 - Mnaajemen } \\
\text { Sumber Daya Manusia }\end{array}$ & 2 & 1 & 1 \\
\hline 4 & $\begin{array}{l}\text { DSS03 - Manajemen } \\
\text { masalah }\end{array}$ & 2 & 1 & 1 \\
\hline 5 & $\begin{array}{l}\text { MEA01 - Mengawasi, } \\
\text { Kengevaluasi, Menilai } \\
\text { Kinerja Dan kesesuaian }\end{array}$ & 2 & 1 & 1 \\
\hline
\end{tabular}

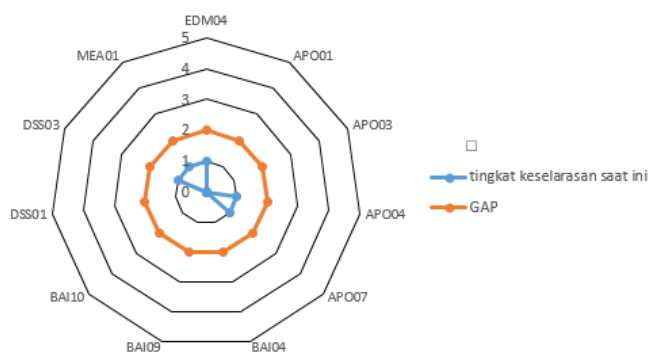

Gambar 5. GAP tingkat keselaraan proses saat ini dan target yang akan dicapai 
Gambar 5 menunjukan tingkat keselarasan tatakelola pemerintah Sulawesi Utara dengan ITRelated Goals pengoptimalan aset TIK, sumber daya dan kapabiltas mencapai tingkat 1 (performed process) dikarenakan $50 \%$ proses yang di nilai sudah mencapai tingkat 1 , hal tersebut menunjukan bahwa proses-proses tata kelola sudah mulai dilaksanakan atau diterapkan sebagaimana mestinya tetapi masih ada 6 proses yang belum mencapai tingkat 1 yakni proses APO01, APO03, BAI04, BAI09, BAI10, dan DSS01.

\section{Rekomendasi Perbaikan}

\section{i. Rekomendasi APO01}

Berdasarkan analisis gap yang didapat dengan level target yang ingin dicapai pada APO01, maka berikut adalah rekomendasi yang dapat penulis berikan untuk meningkatkan tingkat keselarasan TIK pada Pemerintah Sulawesi Utara:

1) Pembuatan peraturan terkait bidang TIK agar pengelolaan faktor pendukung pengolaan system bisa berjalan dengan baik

2) Mengelola perbaikan proses secara berkesinambungan dalam tujuan kinerja dan pembuatan metrik kinerja

\section{ii. Rekomendasi APO03}

Melalui analisis gap yang didapat dengan level target yang ingin dicapai pada APO03, maka berikut adalah rekomendasi yang dapat penulis berikan untuk meningkatkan tingkat keselaran TIK pada Pemerintah Sulawesi Utara:

1) Menyusun Renstra TIK yang terdiri dari proses bisnis, informasi, data, aplikasi dan teknologi dengan tujuan mewujudkan strategi organisasi dan strategi TIK secara efektif dan efisien. Rancangan tersebut mendeskripsikan kondisi saat ini da target yang akan dicapai.

2) Menetapkan acuan arsitektur Rentra TIK mulai dari model proses dan model informasi dalam bidang TIK sehingga domain dasar bisa di deskripsikan melalui Renstra TIK tersebut.

3) Pembuatan pedoman solusi dalam pengembangan rentsra TIK sehingga kebutuhan tatakelola asitektur renstra bisa tecapai dan selaras dengan visi dan misi Pemerintah Sulawesi Utara

\section{iii. Rekomendasi BAI04}

berlandaskan analisis gap yang didapat dengan level target yang ingin dicapai pada BAI04, maka berikut adalah rekomendasi yang dapat penulis berikan untuk meningkatkan tingkat keselaran TIK pada Pemerintah Sulawesi Utara:

1) Menilai dan membuat catatan ketersedian kinerja dan kapasitas dalam Menjaga ketersediaan layanan, manajemen sumber daya yang efisien dan mengoptimalkan kinerja System

2) Membuat penilaian dan scenario terhadap dampak ketersediaan kinerja dan kapasitas terhadap layanan publik

\section{iv. Rekomendasi BAI09}

Bersumber pada analisis gap yang didapat dengan level target yang ingin dicapai pada BAI09, maka berikut adalah rekomendasi yang dapat penulis berikan untuk meningkatkan tingkat keselaran TIK pada Pemerintah Sulawesi Utara:

1) Mengelola lisensi dengan membuat daftar lisensi seluruh perangkat lunak yang ada sehingga penyesuaian dan penempatan lisensi bisa diolah dengan baik

\section{v. Rekomendasi BAI10}

Menurut analisis gap yang didapat dengan level target yang ingin dicapai pada BAI10, maka berikut adalah rekomendasi yang dapat penulis berikan untuk meningkatkan tingkat keselaran TIK pada Pemerintah Sulawesi Utara:

1) mengkoordinasikan dan melaksanakan prosedur operasional antara pengelola infrastruktur jaringan dengan pengguna layanan infrastruktur jaringan maupun vendor

2) membuat SOP dan aktivitas pemantauan dalam mendifinisikan, mempertahankan deskripsi dan hubungan antara sumber daya kunci dan kemampuan yang dibutuhkan untuk penyampaian layanan TIK yang meliputi pengumpulan informasi mengenai konfigurasi, menetapkan baseline, mem-verifikasi dan mengaudit informasi konfigurasi, dan memperbaharui penyimpanan konfigurasi.

\section{vi. Rekomendasi DSS01}

Berdasarkan analisis gap yang didapat dengan level target yang ingin dicapai pada 
DSS01, maka berikut adalah rekomendasi yang dapat penulis berikan untuk meningkatkan tingkat keselaran TIK pada Pemerintah Sulawesi Utara:

1) Instansi pada tahap ini sudah menjalankan proses penjadwalan aktivitas operasional TIK terstruktur dengan tetap dan menginginkan proses secara terukur maka harus melakukan perbaikan pada performa, sumber daya, pengadaan fasilitas yang bertaraf internasional, dan dapat menghasilkan sesuai yang diinginkan.

2) Mengadakan maintenance rutin mingguan pada aset prasarana yang membutuhkan pengawasan ektra berhubungan dengan TIK Aset.

3) Melangsungkan keselamatan dan kesehatan kerja (K3), serta menjamin letak fasilitas TIK aman sesuai prosedur dan spesifikasi pengguna.

4) Membentuk tim audit TIK internal untuk selalu melakukan penilaian dalam penggunaan fasilitas, karena dalam hasil yang peneliti dapatkan audit hanya terfokus pada keuangan, dan kinerja pegawai saja, belum terfokus pada IT itu sendiri.

\section{vii. KESIMPULAN}

\section{A. Kesimpulan}

Kesimpulan penelitian adalah:

i. tingkat keselarasan saat ini (as is) untuk 11 subdomain adalah 6 subdomain mencapai tingkat 1 (Performed Process) dan 5 subdomain mencapai tingkat 0 (Incomplete Process).

ii. tingkat keselarasan yang diharapkan (to-be) untuk 5 subdomain adalah tingkat (2 Manage Process) sedangkan 6 subdomain adalah tingkat 1 (Performed Process)

\section{B. Saran}

Berikut adalah saran yang dapat disampaikan dalam tugas akhir ini :

i. pencapaian tingkat 1 - (Performed Process) Proses yang diimplementasikan harus mencapai tujuan prosesnya. Ketentuan PA (Process Attribute) pada level ini adalah sebagai berikut Pengukuran yang berkaitan dengan tujuan yang sudah dicapai sampai sejauh mana. Pencapaian penuh ditandai dengan tercapainya tujuan.

ii. pencapain tingkat 2 - Proses dikelola (Managed Process) Proses yang diimplementasikan adalah berhasil merencanakan, dimonitor, dan disesuaikan. Produk kerja yang tepat telah ditetapkan, dikontrol dan dipelihara dengan baik.

\section{DAFTAR PUSTAKA}

[1] Direktorat E-goverment (2014) “ Buku Petunjuk Penyusunan Rencana Induk TIK”.Indonesia

[2] Republik Indonesia.2009. Undang-Undang Republik Indonesia Nomor 25 Tahun 2009 tentang Pelayanan Publik. Lembaran Negara RI Tahun 2009, No. 115. Sekretariat Negara. Jakarta.

[3] Republik Indonesia.2003. Intruksi Presiden (Inpres) No 3 Tahun 2003 tentang Kebijakan dan strategi National Pengembangan E-Goverment, No. 115. Sekretariat Negara. Jakarta.

[4] Depkominfo, Peluang Indonesia Untuk Bangkit Melalui Implementasi E-Government, Laguboti, Toba, 2005

[5] Bjorn-Anderson N., "Implementation of Office Systems", North Holland, Amsterdam: Office Systems, 1986.

[6] Richardus Eko Indrajit(2013). “ Tata Kelola Manajemen Teknologi Informasi ”. E-artikel Sistem dan Teknologi Informasi No.999

[7] Taloon and Kenneth L. Kraemer. (2003). Investigating the relationship bettwen strategic aligment and IT business value: the discovery of a paradox. Creating Business Value with Tecnology: Challenges and Solutions. Hershey, PA:Idea Group Publishing, pp.1-22

[8] J. Luftman (2000). Assessing Business-IT Alignment Maturity, Communications of the Information Sytems, 4:99.

[9] H. Wowor and S. Karouw, "Quantifying IT business value: case study of North Sulawesi province, Indonesia," 2012 International Conference on Advanced Computer Science and Information Systems (ICACSIS), Depok, 2012, pp. $167-172$ 
[10] ISACA. (2013). COBIT ®5 : Enabling Proceses. IT Governance Intitute (ITGI), Rolling Meadows, USA

[11] Arif Lutfianto (2014) “ Analisis Tata Kelola teknologi Informasi dengan framework COBIT 5 domain EDM01 pada Politeknik Harapan Bersama Tegal". Universitas Dian Nuswantoro.

[12] Nurrahmi Fitri (2015) “Analisa Tingkat Kapabilitas Tata Kelola Teknologi Informasi Menggunakan Kerangka Kerja Cobit 5 Pada PT. Berlian Jasa Terminal Indonesia”. MMT-ITS, Indonesia.

[13] Abdul Hakim (2014) “ Evaluasi Tata Kelola Teknologi Informasi dengan Framework COBIT 5. Di Kementrian ESDM ( Studi Kasus pada Pusat Data dan Teknologi Informasi ESDM). Sekolah Tinggi Manajemen Informatika dan Komputer Eresha,Indonesia

[14] Burdefira (2013) "Evaluasi Terhadap implementasi Tata Kelola teknologi informasi berdasarkan Framework COBIT pada Pemerintah kota padang".UNP, Indonesia.

[15] Soni Susanto (2015) “perancangan tata kelola ti untuk pelayanan publik pada dinas komunikasi dan informatika surabaya dengan kerangka kerja COBIT ". MMT-ITS, Indonesia

[16] Pasquini, Alex. Galie, Emidio. (2013). " COBIT 5 and the Process Capability Model. Improvements Provided for IT Governance Process" Proceedings of FIKUSZ '13 Symposium for Young Researchers, 2013, 67-76. Obuda University Keleti.

[17] ISACA. (2013). COBIT ®5: Tool-kit. IT Governance Intitute (ITGI), Rolling Meadows, USA

[18] Maskur (2015) “Perancangan Tata Kelola TI dengan menggunakan Framework COBIT 5 (Studi Kasus : Pemerintah Kab.Jeneponto)". Jurnal Teknologi Informasi Dan Komputer Vol 1 No 1

[19] PT GEOMATIK (2014) "Penyusunan Masterplan E-Goverment Provinsi Gorontalo Tahun 2014 2019”. Gorontalo

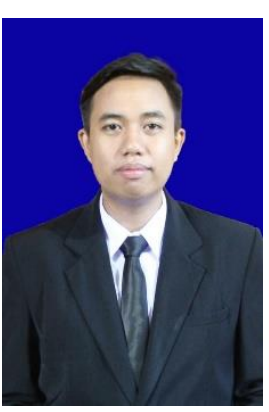

Brian Gamaliel, lahir di Palu, Provinsi Sulawesi Tengah. Anak ke-2 dari 2 bersaudara dengan pendidikan Sekolah Dasar Negeri 7 palu. Penulis lalu melanjutkan ke Sekolah Menengah Pertama Negeri 2 Palu. Lalu ke SMK 3 Negeri Palu dengan Jurusan Teknik Komputer dan Jaringan. Pada tahun 2012 melanjutkan ke Perguruan Tinggi di Universitas Sam Ratulangi dengan mengambil Jurusan Teknik Informatika. Pada Tahun 2016 bulan September sampai Bulan November melakukan Kerja Praktek di Perushaan CV. Mapalus Tech dengan Judul Projek Membuat website Rumah Sakit Umum Liun Kendage Tahuna . Dan Pada Tahun 2016, penulis membuat Skripsi demi memenuhi Syarat Sarjana (S1) dengan penelitian berjudul Pengukuran Keselarsan Tata Kelola Teknologi Informasi Menggunakan Cobit 5 pada Pemerintah Sulawesi Utara, yang dibimbing oleh dua dosen pembimbing yaitu Yaulie D. Y. Rindegan, ST., MM., MSc dan Stanley D.S. Karouw.ST, MTI sehingga pada tanggal 15 Juni 2017 penulis resmi lulus di Teknik Informatika Universitas Sam Ratulangi Manado menyandang gelar Sarjana Komputer dengan Predikat Sangat Memuaskan. 